\title{
Analisis persepsi peternak terhadap kompetensi penyuluh dalam pengembangan usaha peternakan sapi potong Di Kecamatan Bacan Timur Tengah
}

\author{
E.S. Dodengo, J. Lainawa*, G.D. Lenzun, J.M. Tumewu \\ Fakultas Peternakan Universitas Sam Ratulangi Manado 95115 \\ *Korespondensi (corresponding author): jolylainawa@unsrat.ac.id
}

\begin{abstract}
ABSTRAK
Penelitian ini dilaksanakan di Kecamatan Bacan Timur Tengah Desa Bibinoi Kabupaten Halmahera Selatan pada bulan Agustus 2019. Tujuan dari penelitian ini untuk mengetahui tingkat tanggapan petani terhadap kompetensi penyuluh pada kegiatan penyuluhan usaha peternakan sapi potong. Penyuluh pertanian adalah orang yang berperan dalam memberdayakan petani sebagai pelaku utama dalam pembangunan pertanian pada umumnya agar mereka mampu mengembangkan usaha sesuai dengan kemampuan dan sumber daya lokal yang dimiliki.Jenis penelitian yang digunakan yaitu metode Deskriptif kualitatif dengan pendekatan terhadap kegiatan penyuluhan yang dilakukan kepada petani di Kecamatan Bacan Timur Tengah Kabupaten Halmahera Selatan dengan konsentrasi pada Desa Bibinoi karena desa ini memiliki petani yang memelihara ternak sapi. Pemilihan responden dengan mengambil 30 orang peternakm, pengukuran variabel dilakukan dengan menerapkan Skala Likert yang pengukurannya diberi skor pada setiap persepsi. Hasil Penelitian menunjukkan bahwah secara keseluruhan nilai persepsi peternak sapi potong terhadap kompentensi penyuluh di desa bibinoi Kecamatan Bacan Timur Tengah Kabupaten Halmahera Selatan, paling menonjol yaitu kompentensi professional dan kompentensi sosial dengan persentase $100 \%$. Secara keseluruhan persepsi peternak sapi potong terhadap kompentensi penyuluh dilihat dari kompentensi kepribadian, $80 \%$ menilai sangat suka dan 13,33\% menilai suka. Adapun 6,67\% menilai tidak suka. Kompentensi androgogi, 93,33\% meniali Sangat suka dan $6,67 \%$ menilai suka. Kompentensi professional dan Kompentensi sosial $100 \%$ peternak menilai sangant suka. Persepsi peternak terhadap kompentensi penyuluh menunjukan hasil sebagian besar Sangat suka 100\% dan sebagian kecil Tidak suka 6,67\%.
\end{abstract}

Kata kunci : Persepsi Petani Peternak, Kompetensi Penyuluh.

\begin{abstract}
ANALYSIS OF FARMER'S PERCEPTIONS OF EXTENSION COMPETENCY IN BEEF CATTLE BUSINESS DEVELOPMENT IN BACAN DISTRICT, MIDDLE EAST This research was carried out in the Middle East Bacan District, Bibinoi Village, South Halmahera Regency in August 2019. The purpose of this study was to determine the level of farmers' responses to the competence of extension workers in outreach activities in beef cattle farming. Agricultural extension workers are people who play a role in empowering farmers as the main actors in agricultural development in general so that they are able to develop businesses according to their local capabilities and resources. The type of research used is a qualitative descriptive method with an approach to extension activities carried out to farmers in Bacan Timur Tengah District, South Halmahera Regency with a concentration on Bibinoi Village because this village has farmers who raise cattle. Selection of respondents by
\end{abstract}


taking 30 breeders, variable measurement was carried out by applying a Likert scale whose measurements were scored on each perception. The results showed that the overall perception value of beef cattle breeders on the competence of extension workers in Bibinoi village, Bacan Timur Tengah District, South Halmahera Regency, the most prominent was professional competence and social competence with a percentage of $100 \%$. Overall, the perceptions of beef cattle breeders on the competence of extension workers were seen from the personality competency, $80 \%$ rated very like and $13.33 \%$ rated like mean while, $6.67 \%$ said they didn't like it. Competence, $93.33 \%$ rated very like and $6.67 \%$ rated like. Professional competence and social competence $100 \%$ of breeders rated very like it. Farmers 'perceptions of extension agents' competency showed the results were mostly very like $100 \%$ and a small proportion did not like $6.67 \%$ technology.

Keywords: Farmer's Perception, Farmer's Competence.

\section{PENDAHULUAN}

Penyuluh pertanian adalah orang yang berperan dalam memberdayakan petani sebagai pelaku utama dalam pembangunan pertanian pada umumnya agar mereka mampu mengembangkan usaha sesuai dengan kemampuan dan sumber daya lokal yang dimiliki. Penyuluhan pertanian yang diberikan melalui sistem pendidikan non-formal bertujuan untuk mengubah perilaku petani agar dapat mengelola usaha pertaniannya dengan baik dan dapat berkembang (sustainable), sehingga lebih sejahtera.

Petani adalah pelaku utama dalam kegiatan produksi pertanian, bagian dari masyarakat Indonesia yang perlu ditingkatkan kesejahteraan dan kecerdasannya melalui kegiatan penyuluhan. Dengan adanya penyuluhan diharapkan semua informasi pertanian yang berkembang dapat diserap dan diterima oleh petani, semakin banyak informasi yang dimanfaatkan oleh petani maka semakin efektif penyuluhan tersebut, Sambow et al. (2020).

Kompetensi penyuluh pertanian diuraikan pada tugas pokok dan fungsi seorang penyuluh dalam membantu petani mengembangkan usahanya, karena kompetensi merupakan kemampuan yang dimiliki penyuluh, baik kompetensi teknis maupun kompetensi manajerial. Kompetensi penyuluh pertanian perlu didukung dengan kemampuan intelektual (cognitif), kemampuan yang berkaitan Huda (2011).

Khuseno (2019), menegaskan bahwa dalam individu terdapat lima tipe kompetensi yaitu motif (motives), sifat bawaan (traits), konsep diri (self concept), pengetahuan (knowledge), dan keterampilan (skills). Dengan adanya kompetensi seorang penyuluh diharapkan mampu menyelesaikan tugas-tugasnya dengan baik dalam menyelenggarakan penyuluhan pertanian. Kenyataan di lapangan masih banyak penyuluh pertanian memiliki kompetensi yang rendah dalam melaksanakan tugasnya sebagai agen perubahan di bidang pembangunan pertanian. Kenyataan ini dipengaruhi oleh berbagai kebijakan di bidang pertanian yang menentut seorang penyuluh bekerja bukan pada bidang yang ditekuninya. Menurut Anwas (2013), untuk meningkatkan kompetensi banyak upaya yang dapat dilakukan diantaranya melalui peningkatan pendidikan, pelatihan, diskusi antar penyuluh, penyediaan sarana dan prasarana penyuluhan yang diasumsikan memiliki pengaruh yang signifikan terhadap peningkatan kompetensi penyuluh pertanian. Hal ini membutuhkan penyuluh pertanian yang terintegrasi pada pelaksanaan tugas pokok dan fungsi penyuluh pertanian dalam merencanakan, mengorganisasikan, dan mengevaluasi program penyuluh pertanian, Bahua et al. (2010). Permasalahan dilapangan yang berkaitan dengan kegiatan penyuluhan 
ialah masih kurangnya perilaku pengetahuan, sikap dan ketrampilan dalam keberhasilan beternak. Juriah (2019), mengemukakan bahwa persepsi seseorang merupakan proses aktif yang memegang peranan, bukan hanya stimulus yang mengenainya tetapi juga individu sebagai satu kesatuan dengan pengalamanpengalamannya, motivasi serta sikapnya yang relevan dalam menanggapi stimulus. Individu dalam hubungannya dengan dunia luar selalu melakukan pengamatan untuk dapat mengartikan rangsangan yang diterima dan alat indera dipergunakan sebagai penghubungan antara individu dengan dunia luar.

Priyono et al. (2015), dalam penelitiannya menyatakan bahwa kontribusi tingkat teknologi, dukungan kelembagaan, dan peran penyuluhan secara simultan memiliki pengaruh nyata terhadap tingkat adopsi oleh peternak. Jika pengaruh penyuluhan kurang baik, maka penyuluh harus meningkatkan dan memperbaiki kinerjanya, sebaliknya jika penyuluh dinilai sudah baik, berarti penyuluh tersebut sudah menjalankan tugas dan fungsinya dengan baik. Tujuan penelitian ini adalah untuk menganalisis persepsi peternak terhadap kompentensi penyuluh di Desa Bibinoi.

Adapun dalam penelitian ini penulis merumuskan masalah yaitu bagaimana kompetensi penyuluh pertanian dalam memberikan penyuluhan tentang usaha sapi potong kepada petani di Kecamatan Bacan Timur Tengah Kabupaten Halmahera Selatan. Tujuan dari penelitian ini adalah untuk mengetahui tingkat tanggapan petani terhadap kompetensi penyuluh pada kegiatan penyuluhan usaha peternakan sapi potong.

\section{METODE PENELITIAN}

\section{Tempat dan waktu penelitian}

Penelitian ini telah dilaksanakan pada usaha peternakan sapi potong yang dilakukan oleh petani di Kecamatan Bacan Timur Tengah Kabupaten Halmahera
Selelatan. Waktu penelitian akan dilaksanakan selama 1 bulan.

\section{Metode penelitian}

Metode penelitian yang digunakan yaitu metode Deskriptif kualitatif. Penggunaan pendekatan ini bertujuan untuk mendeskripsikan perilaku orang, peristiwa lapangan, serta kegiatan-kegiatan tertentu secara terperinci dan mendalam. Adapun yang dimaksud dengan penelitian deskriptif yaitu suatu penelitian sekedar untuk menggambarkan suatu variabel yang berkenaan dengan masalah yang diteliti terhadap kegiatan penyuluhan, yang dilakukan dengan survei, Paturochman (2012), Tujuan survei adalah untuk mengumpulkan sejumlah data melalui alat pengukur wawancara.

\section{Teknik pengumpulan data}

Data yang akan dibutuhkan adalah data primer dan data sekunder, dimana data primer diperoleh dengan teknik wawancara mendalam kepada 30 peternak sapi potong di kecamatan Bacan Timur Tengah dengan syarat pernah mendapat penyuluhan peternakan sapi potong dan memiliki usaha peternakan sapi potong minimal 2 ekor dengan lama usaha diatas 3 tahun. Selain itu data tentang profil penyuluh berkaitan dengan latar belakang organisasi penyuluh, pendidikan dan keadaan usia penyuluh. Data sekunder diperoleh dari data kedaan wilayah, keadaan SDM Petani, keadaan perkembangan populasi yang diperoleh pada kantor Kecamatan Bacan Timur Tengah serta hasil penelitian terkait melalui internet.

\section{Analisis data}

Data yang telah diperoleh akan dilakukan analisis dengan mengikuti pedoman metode rating skala Likert, terhadap persepsi petani pada kemampuan intelektual teknologi usaha peternakan sapi potong yang dinilai berdasarkan alasan dikemukakan petani. Pengukuran persepsi menggunakan skala Likert ini dibedakan 
atas empat skala sebagai berikut, Dali et al. (2017):

1. kategori 1 (rendah $)=1$ alasan

2. kategori 2 (sedang) $=2$ alasan

3. kategori 3 (tinggi) $=3$ alasan

4. kategori 4 (sangat tinggi) $\geq 4$ alasan.

\section{Variabel}

Variabel yang diteliti dalam penelitian ini yaitu sebagai berikut:

1. Kompentesi kepribadian, Kompetensi kepribadian merupakan suatu hal yang dapat menjadikan seseorang bersemangat karena dalam menjalani apa yang ia kerjakan berdasarkan kepribadiannya

2. Kompentensi Andragogi, diartikan sebagai kebulatan pengetahuan, keterampilan, dan sikap yang diwujudkan dalam bentuk tindakan cerdas dan penuh tanggung jawab yang dimiliki seseorang yang memangku jabatan guru sebagai profesi.

3. Kompetensi professional, sangat berkaitan erta dengan kemamp dalamuan menguasai meteri pada bidang studi manapun dengan berbagai substansi keilmuan lainnya sebagai guru.

4. Kompetensi sosial ialah kemampuan seorang guru dan Penyuluh untuk berkomunikasi dan berinteraksi secara efektif dan efisien dengan peserta didik, orang tua, dan masyarakat sekitar.

\section{Letak geografis}

Letak geografis Kabupaten

Halmahera Selatan Administratif dan Kondisi Fisik Secara geografis Kabupaten Halmahera Selatan termasuk kabupaten kepulauan karena wilayahnya di dominasi lautan. Wilayah daratan tersebar di pulaupulau yang tergolong pulau kecil. Ada tujuh pulau/kepulauan utama dengan luas masing masing Pulau Obi $\left(3.111 \mathrm{~km}^{2}\right)$, Pulau Bacan $\left(2.053 \mathrm{~km}^{2}\right.$ ), Pulau Makian $\left(113,12 \mathrm{~km}^{2}\right)$, Pulau Kayoa $\left(1142 \mathrm{~km}^{2}\right)$, Pulau Kasiruta $\left(708 \mathrm{~km}^{2}\right.$ ), Pulau Mandioli $\left(260 \mathrm{~km}^{2}\right)$ dan semenanjung Pulau Halmahera yang masuk wilayah Kabupaten Halmahera Selatan seluas kurang lebih $2.615 \mathrm{~km}^{2}$.

Permukiman di Kabupaten Halmahera Selatan hampir semua terletak di wilayah pesisir. Dari 249 Desa yang ada, hanya $4 \%$ Desa yang tidak dikategorikan sebagai Desa pantai, sedangkan $96 \%$ lainnya merupakan Desa pantai. Keseluruhan Desa tersebut berada pada lahan diketinggian kurang dari 500 meter dpl, BPS Kabupaten Halmahera Selatan (2019).

\section{Kependudukan}

Penduduk Kecamatan Bacan Timur Tengah pada tahun 2015 sebesar 5.948 jiwa, yang terdiri atas 3.060 jiwa laki-laki dan 2.888 jiwa perempuan. Dengan luas wilayah Kecamatan Bacan Timur Tengah

\section{HASIL DAN PEMBAHASAN}

Tabel 1. Luas Daerah Menurut Desa di Kecamatan Bacan Timur Tengah, 2017

\begin{tabular}{|c|c|c|c|}
\hline No & Desa & Luas km2 & $\%$ \\
\hline 1 & Tawa & 44,8 & 16,2 \\
\hline 2 & Songa & 39,4 & 14,3 \\
\hline 3 & Bibinoi & 54,1 & 19,6 \\
\hline 4 & Tabapoma & 41,2 & 14,9 \\
\hline 5 & Tutupa & 26,5 & 9,6 \\
\hline 6 & Tomara & 34,6 & 12,5 \\
\hline 7 & Wayatim & 35,7 & 12,9 \\
\hline & Jumlah & 276,3 & 100,0 \\
\hline
\end{tabular}


Tabel 2. Jumlah Penduduk Menurut Desa, Jenis Kelamin, Dan Banyaknya Keluarga Di Kecamatan Bacan Timur Tengah.

\begin{tabular}{clrrcc}
\hline No & Desa & Laki- laki & Perempuan & Jumlah & Keluarga \\
\hline 1 & Tawa & 451 & 390 & 841 & 241 \\
2 & Songa & 644 & 597 & 1241 & 335 \\
3 & Bibinoi & 1091 & 1050 & 2141 & 583 \\
4 & Tabapoma & 284 & 281 & 565 & 145 \\
5 & Tutupa & 337 & 345 & 682 & 181 \\
6 & Tomara & 428 & 413 & 841 & 216 \\
7 & Wayatim & 193 & 185 & 378 & 92 \\
\hline & Total & 3,428 & 3,261 & 6.689 & 1,793 \\
\hline
\end{tabular}

sekitar 276,3 kilometer persegi, rata-rata tingkat kepadatan penduduk Halmahera Selatan sebesar 22 orang per kilometer persegi. Desa dengan penduduk terpadat adalah Desa Bibinoi yakni sebanyak 35 orang per kilometer persegi sedangkan yang paling rendah adalah Desa Wayatim dengan kepadatan 8 orang per kilometer persegi.

Rasio jenis kelamin di Kecamatan Bacan Timur Tengah sebesar 105,95. Angka rasio tersebut menandakan di Kecamatan Bacan Timur Tengah, jumlah penduduk laki - laki lebih banyak dari pada jumlah penduduk perempuan, Arsip Kantor Desa Bibinoi Tahun (2019)

Rasio jenis kelamin adalah perbandingan antara banyaknya penduduk laki-laki dengan banyaknya penduduk perempuan pada suatu daerah dan waktu tertentu. Biasanya dinyatakan dengan banyaknya penduduk laki-laki untuk 100 Penduduk perempuan Rata-rata pertumbuhan penduduk adalah angka yang menunjukkan tingkat pertambahan penduduk per tahun dalam jangka waktu tertentu.

\section{Karakteristik peternak}

1. Umur.

Berdasarkan hasil penelitian bahwa rata-rata umur petani peternak yaitu 46 tahun atau berada pada kisaran 39-52 tahun dimana hal ini menunjukan bahwa umur petani peternak berada pada kategori produktif dengan presentase $100 \%$.
Menurut Makatita (2013), bahwa banyaknya peternak yang berada pada kelompok umur produktif merupakan modal utama dalam mengembangkan suatau usaha peternakan. Usia produktif sangat penting bagi pelaksanaan usaha karena usia ini peternak mampu mengkordinasi dan mengambil langkah yang efektif. hal tersebut didukung oleh pendapat Anggoro (2012), yang menyatakan bahwah salah satu karakteristik peternak yang mempengaruhi kecepatan adopsi adalah umur.dalam mengembangkan sumberdaya peternak dibutuhkan kehadiran penyuluh yang memiliki kompetensi profesional yang memadai.

2. Tingkat Pendidikan.

Hasil penelitian menunjukan bahwah tingkat pendidikan petani peternak di kecamatan bacan timur tengah paling banyak pada lulusan tingkat SMP yaitu sebesar $36,67 \%$ atau sebanyak 11 orang, tingkat SMA sebesar $26,67 \%$ atau sebanyak 8 orang, Tingkat SD sebesar $16,67 \%$, dan tingkat S1 sebesar sebesar $10 \%$ hal ini berarti bahwa tingkat pendidikan petani peternak masih tergolong bagus yang hal ini mempengaruhi tingkat penetahuan yang memadai bagi petani peternak tersebut. Hal ini senada dengan apa yang dikemukakan oleh Room (2017), tingkat tinggi rendahnya pendidikan petani akan menanamkan sikap yang menuju 
penggunaan praktek pertanian yang lebih modern.

Mengenai tingkat pendidikan petani, dimana mereka yang berpendidikan tinggi relative lebih cepat dalam melaksanakan suatu usaha.

\section{Analisis kompetensi kepribadian penyuluh}

Berdasarkan kegiatan penelitian yang dilakukan mengenai persepsi peternak terhadap kompentensi kepribadan. Dalam kegiatan penyuluhan, dan bagaimana penyuluh dapat meluangkan waktunya untuk membantu peternak dalam berusaha tani di Desa Bibinoi Kecamatan Bacan Timur Tengah Kabupaten Halmahera Selatan, maka didapatkan hasil analisis yang di sajikan dalam table 3 .

Tabel 3, menunjukan bahwa persepsi petenak sapi potong terhadap kompentensi penyuluh dari segi kompentensi kepribadian diketahui bahwah sebagian besar responden sejumlah 24 responden (80\%) menyatakan Sangat suka. Dan 4 responden (13\%) suka adapun 2 responden $(6,67 \%)$ tidak suka dalam. Hal ini menunjukan bahwah penyuluh dilokasi penelitian sudah baik dalam hal kepribadian yang dilihat oleh peternak sapi potong.

\section{Kompetensi androgogi (kompetensi mengarahkan)}

Menurut Mushafah (2011) mengatakan kompetensi andragogi adalah Kemampuan mengelola peserta didik meliputi: Pemahaman wawasan atau landasan pendidikan, Pemahaman tentang peserta didik, Perancanganpembelajaran, akan Pelaksanaanpembelajaran

mendidik, dialogis Pengembangan peserta didik untuk mengaktualisasi berbagai potensi yang dimilikinya

Penilaian persepsi peternak terhadap kompentensi andragogi (mengarahkan) yang diukur dalam penelitian ini adalah kemampuan penyuluh dapat mengidentifikasi kebutuhan peternak sapi potong dan penyuluh menjelaskan pengetahuan dan informasi baru dalam usahatani kepada peternak sapi potong. Adapun hasil penilaian tersebut disajikan pada tabel 4.

Tabel 4, menunjukan bahwa 28 responden $(93,33)$ menyatakan Sangat Suka. Sedangkan jumlah 2 responden $(6,67)$ mempersepsikan Suka, dengan demikian pada professional memiliki

Tabel 3. Persepsi Responden Terhadap Kompentensi Kepribadian Penyuluh

\begin{tabular}{lcc}
\hline \multicolumn{1}{c}{ Persepsi } & Responden (Orang) & Presentase (\%) \\
\hline Sangat suka & 24 & 80 \\
Suka & 4 & 13,33 \\
Ragu ragu & - & - \\
Tidak suka & 2 & 6,67 \\
\hline Total & 30 & 100 \\
\hline
\end{tabular}

Tabel 4. Persepsi Responden Terhadap Kompentensi Androgogi Penyuluh

\begin{tabular}{lcc}
\hline \multicolumn{1}{c}{ Persepsi } & Responden & Presentase $(\%)$ \\
\hline Sangat suka & 28 & 93,33 \\
Suka & 2 & 6,67 \\
Ragu ragu & - & - \\
Tidak suka & - & - \\
\hline Total & 30 & 100 \\
\hline
\end{tabular}


kompetensi yang memadai, termasuk aparatur pelaksana kegiatan penyuluhan dapat disimpulkan bahwah persepsi peternak terhadap kompentensi androgogi penyuluh sangat baik

\section{Kompetensi profesional}

Menurut Bahua et al. (2010), program penyuluhan pembangunan yang efektif dan efisien dapat dikembangkan oleh tenagatenaga profesional di bidang penyuluhan pembangunan $\mathrm{Hal}$ ini hanya memungkinkan apabila program penyuluhan di wadahi oleh sistem kelembagaan penyuluhan yang jelas dan pelaksanaanya didukung oleh tenagatenaga yang kompeten di bidang penyuluhan. Peningkatan kompetensi penyuluh dalam pembangunan pertanian, bisa dikondisikan melalui berbagai upaya seperti:

1. meningkatkan efektivitas pelatihan bagi penyuluh,

2. meningkatkan pengembangan diri penyuluh melalui peningkatan kemandirian belajar dan pengembangan karir penyuluh,

3. meningkatkan dukungan terhadap penyelenggaraan penyuluhan seperti dukungan kebijakan pemerintah daerah terhadap pendanaan penyuluhan, dukungan peran kelembagaan, dukungan teknologi dan sarana penyuluhan, pola kepemimpinan yang berpihak petani

4. memotivas pribadi penyuluh untuik selalu meningkatkan prestasi kerja (kinerja penyuluh) dan mengikuti perubahan lingkungan strategis yang ada.

5. Professional atau memiliki kompetensi yang memadai.
Dengan demikian untuk terjadinya percepatan pembangunan peternakan di wilayah tersebut, khususnya di dalam mengembangkan sumber daya peternak dibutuhkan kehadiran penyuluh yang memiliki kompetensi profesional yang memadai.

Penilaian persepsi peternak terhadap kompentensi profesional yang diukur dalam penelitian adalah penyuluh mampu menyadarkan kebutuhan belajar peternak sapi potong dan penyuluh mampu merencanakan kegiatan pembelajaran yang menarik dan mudah di mengerti, penyuluh juga mengunakan cara-cara belajar yang menarik dan mudah dimengerti. Adapun hasil penilaian tersebut disajikan pada tabel 5.

Tabel 5 Hasil analisis persepsi peternak tehadap kompentensi professional Menunjukan bahwa persepsi peternak terhadap kompentensi professional dinilai oleh 30 responden pada kategori Sangat suka. Ditinjau dari indikator yang diukur, maka hasil penelitian menunjukan bahwa semua pertanyaan yang ada pada koisoner yang diberikan kepada peternak sangant baik di nilai oleh perternak.

\section{Kompetensi sosial}

Kurnia et al. (2010), kompetensi sosial menyangkut kemampuankemampuan berinteraksi/berhubungan sosial, melayani, bermitra, bekerjasama dan bersinergi, mengembangkan kesetiakawanan, kohesif, dan mampu saling percaya mempercayai.

Kompentensi sosial dapat dirinci menjadi beberapa indikator, yaitu: bersikap inklusif dan betindak objektif,

Tabel 5. Persepsi Responden Terhadap Kompentensi Profesional Penyuluh

\begin{tabular}{lcc}
\hline \multicolumn{1}{c}{ Persepsi } & Responden & Presentase $(\%)$ \\
\hline Sangat suka & 30 & 100 \\
Suka & - & - \\
Ragu ragu & - & - \\
Tidak suka & - & - \\
\hline Total & 30 & 100 \\
\hline
\end{tabular}


Tabel 6. Persepsi Responden Terhadap Kompentensi Sosial Penyuluh

\begin{tabular}{lcc}
\hline \multicolumn{1}{c}{ Persepsi } & Responden & Presentase (\%) \\
\hline Sangat suka & 30 & 100 \\
Suka & - & - \\
Ragu ragu & - & - \\
Tidak suka & - & - \\
\hline Total & 30 & 100 \\
\hline
\end{tabular}

Tabel 7. Rekapitulasi Nilai Persepsi Peternak Terhadap Kompentensi Penyuluh

\begin{tabular}{|c|c|c|c|c|c|}
\hline \multirow[b]{2}{*}{ No } & \multirow{2}{*}{$\begin{array}{l}\text { Kompetensi } \\
\text { Penyuluh }\end{array}$} & \multicolumn{4}{|c|}{ Kategori Nilai } \\
\hline & & $\begin{array}{c}\text { Sangat } \\
\text { Suka (\%) }\end{array}$ & Suka (\%) & Ragu-Ragu (\%) & Tidak Suka (\%) \\
\hline 1 & $\begin{array}{l}\text { Kompetensi } \\
\text { Kepribadian }\end{array}$ & 80 & 13,33 & - & 6,67 \\
\hline 2 & $\begin{array}{c}\text { Kompetensi } \\
\text { Andragogi }\end{array}$ & 93,33 & 6,67 & - & - \\
\hline 3 & $\begin{array}{l}\text { Kompetensi } \\
\text { Profesional }\end{array}$ & 100 & - & - & - \\
\hline 4 & $\begin{array}{l}\text { Kompetensi } \\
\text { Sosial }\end{array}$ & 100 & - & - & - \\
\hline
\end{tabular}

beradaptasi dengan lingkungan tempat bertugas dan dengan lingkungan masyarakat, berkomunikasi secara efektif agar dapat dimengertih oleh masyarakat atau peternak. Adapun hasil penilaian peternak terhadap penyuluh yang dilihat dari kompentensi sosial yang disajikan dalam tabel 6 .

\section{Rekapitulasi hasil analisis persepsi}

Berdasarkan hasil analisis persepsi peternak terhadap kompentensi penyuluh pada masing-masing sup indikator penilaian yaitu Kompentensi kepribadian, kompentensi andragogi, kompentesi professional, kompentensi sosial maka di dapatkan hasil keseluruhan penilaian yang disajikan pada tabel 7 .

Tabel 7 menunjukan bahwah secara keseluruhan nilai persepsi peternak sapi potong terhadap kompentensi penyuluh di Desa Bibinoi Kecamatan Bacan Timur Tengah Kabupaten Halmahera Selatan paling menonjol yaitu kompentensi professional dan kompentensi sosial dengan persentase $100 \%$. Berdasarkan persentase nilai persepsi peternak terhadap keseluruhan aspek kompentensi penyuluh.

\section{KESIMPULAN}

Berdasarkan hasil analisis persepsi peternak sapi potong terhadap kompentensi penyululuh pada 30 responden yang ada di Desa Bibinoi Kecamatan Bacan Timur Tengah Kabupaten Halmahera Selatan maka dapat disimpulkan sebagai berikut:

1. Secara keseluruhan persepsi peternak sapi potong terhadap kompentensi penyuluh dilihat dari kompentensi kepribadian, $80 \%$ menilai Sangat suka dan $13,33 \%$ menilai Suka. Adapun $6,67 \%$ menilai Tida suka,. Kompentensi, 93,33\% meniali Sangat suka dan $6,67 \%$ menilai Suka. Kompentensi professional dan Kompentensi sosial $100 \%$ peternak menilai Sangant suka. 
2. Persepsi peternak terhadap kompentensi penyuluh menunjukan hasil sebagian besar Sangat suka $100 \%$ dan sebagian kecil Tidak suka 6,67\%.

\section{DAFTAR PUSTAKA}

Anggoro. S, 2012. Faktor-Faktor Yang Mempengaruhi Kinerja Penyuluh Dalam Pemanfaatan Cyber Extensiondi Kabupaten Bogor. Tesis Program Pascasarjana UNS.

Anwas, 2013, kompetensi penyuluh pertanian dalam memberdayakan petani. Jurnal Matematika, Saint dan Teknologi, 12(1):46-55.

Bahua. M.I, A. Jahi, P.S. Asngari, A. Saleh dan I.G.P. Purnaba. 2010. Faktor-faktor yang mempengaruhi kinerja penyuluh pertanian dan dampaknya pada prilaku petani jagung di Provinsi Gorontalo. Jurnal Ilmiah Agropolitan. 3(1): 293-303.

BPS Kabupaten Halmahera Selatan 2019.

Dali I, F.S. Oley, A.K. Rintjap dan J.M. Tumewu, 2017. Hubungan kinerja penyuluh pertanian lapangan dengan keberhasilan peternak sapi potong di Kecamatan Kwandang Kabupaten Gorontalo Utara. Jurnal Zootek, 37(2) : 403-414.

Huda. N, 2011. Pengembangan kompetensi personal penyuluh pertanian dalam pendidikan tinggi terbuka dan jarak jauh (PTTJJ) Universitas Terbuka. Paper Presented At The Seminar Nasional Matematika, Sains dan Teknologi, Tangerang Selatan.

Juriah. S, 2019. Pengaruh dimensi eksternal persepsi terhadap mutu layanan di Fakultas Kedokteran Universitas Lampung. Jurnal Ekonomi \& Pendidikan, 16(2):2433.

Kantor Desa Bibinoi. 2019. Arsip Kantor Desa Bibinoi
Kurnia. S dan Ingdraningsi. 2010. Kinerja penyuluh dari perspektif petani dan eksistensi penyuluh swadaya sebagai pendamping penyuluh pertanian. Jurnal Analisis Kebijakan Pertanian, 8(4):303-321.

Khuseno. T. M, 2019. Pengaruh pelatihan dan lingkungan organisasi terhadap kompetensi serta dampaknya terhadap kinerja penyuluh pertanian (Studi Pada Dinas Pertanian Dan Peternakan Daerah Provinsi Sulawesi Utara). AgriSosioekonomi. 15(3): 541-552.

Makatita. J. 2013. Hubungan antara karakteristik peternak dengan skala usaha pada usaha peternakan kambing di Kecamatan Leihitu Kabupaten Maluku Tengah. Jurnal Agrinimal. 3(2):78-83.

Musafah J, 2011. Peningkatan Kompetensi Guru Melalui Pelatihan Dan Sumber Belajar Teori dan Praktik, Jakarta : Kencana.

Paturochman. M. 2012. Penentuan Jumlah dan Teknik Pengambilan Sampel. Unpad Press, Bandung. 55-56.

Priyono. W, Sugiyanto dan M. Purnomo, 2015. Faktor-faktor yang berkontribusi terhadap kinerja dan kompetensi penyuluh pertanian pada jenjang jabatan penyuluh pertanian ahli. Jurnal Habitat. 27(2):85-9.

Room. M.J.V, 2017. Adopsi inovasi PTT padi sawah di Kabupaten Maluku Tengah Provinsi Maluku. Prosiding Seminar Nasional.

Sambow. S.A.S, E.P. Manginsela dan J.S. Tambas. 2020. Analisis kinerja penyuluh pertanian berdasarkan persepsi kelompok tani di Kelurahan Taratara Satu Kecamatan Tomohon Barat Kota Tomohon. Agri-Sosioekonomi. 16(3):403-412. 